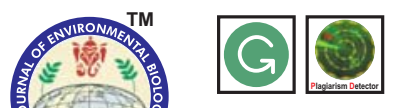

\title{
Using bubble respirometer to monitor microbial activity in passive bioventing system
}

\section{Authors Info}

M.H. Liu*, K.H. Li and B.Y. Chen

Department of Environmental Engineering and Management, Chaoyang University of Technology, Taichung, 41349, Taiwan

${ }^{*}$ Corresponding Author Email : jliu@cyut.edu.tw

Key words

Bioventing system, Bubble respirometer, Microbial activity,

Pseudomonas putida

Publication Info

Paper received: 21.12 .2015

Revised received: 08.04.2016

Re-revised received: 16.06 .2016

Accepted: 05.08.2016

\section{Abstract}

Aim : The study aimed to investigate the relationship between the diesel degradation efficiency in soil and microbial activity during the wind-driven bioventing remediation. The study also aimed to compare the indicators of cumulative oxygen uptake and 24-hr oxygen uptake rate with the analysis results of diesel concentration.

Methodology: A self-made wind-driven bioventing equipment was used as passive bioventing device.In the wind-driven bioventing pilot study for highly diesel contaminated soil (approximately 20,000 mg kg-1), the bubble respirometer collocated with the bioslurry method was used to monitor the microbial activity in soil. The diesel concentration was analyzed by GC/FID.

Results: The result of respiration assays showed that the microbial activities of Bacillus subtilis and Pseudomonas putida, which are capable of degrading diesel, could be consecutively bioaugmented for two weeks, and that of Achromobacter xylosoxidans could be consecutively bioaugmented for three weeks after adding individual microorganism. While appropriate amount of nutrients were added in the pilot, the cumulative oxygen uptake in the Pseudomonas putida set elevated from 219 $\mathrm{mg}-\mathrm{O}_{2}$ to $328 \mathrm{mg}-\mathrm{O}_{2}$ in one week that inferred the microbial activity of Pseudomonas putida and which could be elevated rapidly in a highly diesel contaminated environment. However, the 24-hour oxygen uptake rate in the Achromobacter xylosoxidans set could be maintained in the first three weeks between 4.8 $\mathrm{mg}-\mathrm{O}_{2} \mathrm{hr}^{-1}$ and $5.0 \mathrm{mg}-\mathrm{O}_{2} \mathrm{hr}^{-1}$ that illustrated the microbial activity of Achromobacter xylosoxidans, which was the highest among three microorganisms in the highly diesel contaminated environment.

Interpreration: The research results demonstrated a positive correlation between the diesel degradation efficiency and 24-hour average oxygen uptake rate of microorganisms during the experiment, suggesting that the 24-hour average oxygen uptake rate could be used as an indicator of microbial activity.

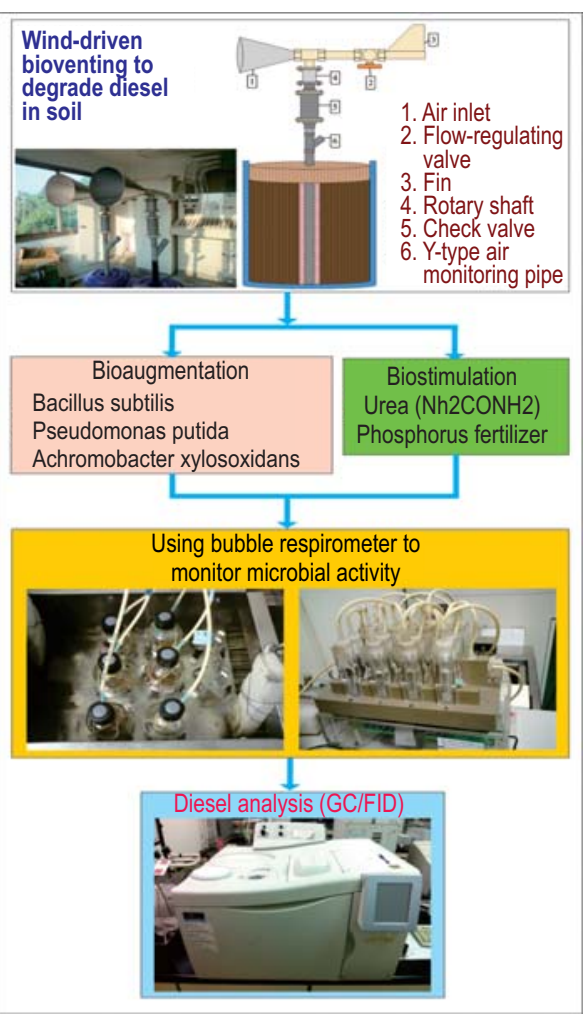




\section{Introduction}

The bioventing method converts vadose zone contaminated soil into a ventilated environment by supplying oxygen and nutrients to facilitate the growth of aerobic microorganisms and to sustain microbial activity which mainly degrade petroleum contamination (Brown et al., 1996). The venting not only removes petroleum contaminants by physical means, but also enhances microbial activity and promotes biodegradation of petroleum contaminants (Texas Research Institute, 1980). Both biostimulation and bioaugmentation technologies operate either through addition of nutrients or enhanced aeration (biostimulation), or through addition of microorganism (bioaugmentation). As such these approaches seek to ensure successful remediation of the site by enhancing the microbial activity under appropriate environmental conditions (Boopathy, 2000). Nine bacterial strains including Bacillus subtilis were isolated from the polluted stream which could degrade crude oil (Adebusoye et al., 2007). Szulc et al. (2014) demonstrated that bioaugmentation of Pseudomonas putida contributed to the highest diesel oil biodegradation efficiency, even the benefits of bioaugmentation was found in a diesel-polluted clay-rich soil (Masy et al., 2014).

Pseudomonas putida and Pseudomonas fluorescens were selected as a coculture to degrade benzene, toluene, ethylbenzene, and xylenes under various growth conditions (Shim, 2005). The literature also illustrated that addition of nutrients were necessary to enhance biodegradation of oil pollutant (Kim et al., 2005). On the other hand, excessive nutrient concentrations can also inhibit the biodegradation activity (Chaillan et al., 2006; Chaîneau et al., 2005). Urea is usually added as a nitrogen source for cellular growth, but it can also serves as an electron acceptor (Leeson and Hinchee, 1997). Literature also indicates that the application of biosolids that contain nutrients, organic matters, and microorganisms had positive effect on the enhancement of biodegradation rate of toluene and naphthalene in the contaminated soil (Chang et al., 2009). Nutrient introduction (biostimulation) promoted a positive effect on microbial population for the microbial consortium consisting Achromobacter xylosoxidans (Colla et al., 2014). The results also indicate that the edaphic community structure and dynamics were different according to the treatments employed. However, carbon dioxide evolution demonstrated insignificant difference in soil microbial activity between biostimulation and bioaugmentation treatments.

Microorganisms in soil consume oxygen and produce carbon dioxide during respiration and the rate has proved to have correlation with the degradation rate of hydrocarbon (Cookson, 1995; Plaza, 2005). By monitoring the amount of oxygen uptake or titrating absorbed carbon dioxide in the potassium hydroxide $(\mathrm{KOH})$ solution, the microbial activity and the degradation efficiency can be evaluated (Balba et al., 1998). Cumulative oxygen uptake and oxygen uptake rate are often used as indicators of respiration monitoring (Chang et al., 2009). Relationship between oxygen uptake and microbial activity on the biodegradation of diesel was studied by Nwankwo et al. (2014). The amount of oxygen consumed during microbial activities was computed and the rate of dissolved oxygen concentration was calculated, the specific oxygen uptake rate was high, while high diesel concentration existed in the soil.

In view of the above, the present study was carried out to investigate the effect on microbial activity in diesel-contaminated soil after adding microorganisms and nutrients in passive bioventing pilot. Study also aimed to compare the indicators of cumulative oxygen uptake and 24-hr oxygen uptake rate with the analysis results of diesel concentration by using GC/FID. By means of evaluating a correlation between oxygen uptake and diesel degradation, and constructing an appropriate indicator of microbial activity, which can be utilized for an efficient and effective monitoring of microbial activity at diesel contaminated sites.

\section{Materials and Methods}

Passive bioventing equipment : It is a self-made wind driven bioventing equipment, introducing oxygen-containing air from atmosphere into the vadose zone. In appearance, it has a trumpet-shaped inlet to inhale air from the environment, a fin at the end to automatically aim at the wind direction, and a flowregulating valve to adjust the amount of air. It is fixed underground casing by ropes and clips (Fig. 1).

Construction of bioventing pilot sets: Five bioventing pilot sets for highly diesel contaminated soil (approximately $20,000 \mathrm{mg} \mathrm{kg}^{-1}$ ) were built in this research. Soil was obtained from a contaminated site in Taichung, Taiwan. On the basis of soil texture analysis and element analysis, the soil is concluded as was sandy loam with a $C: N: P$ ratio of 1000:10:1. After one month of insulation, the oxygen concentration of these pilot sets was brought down to

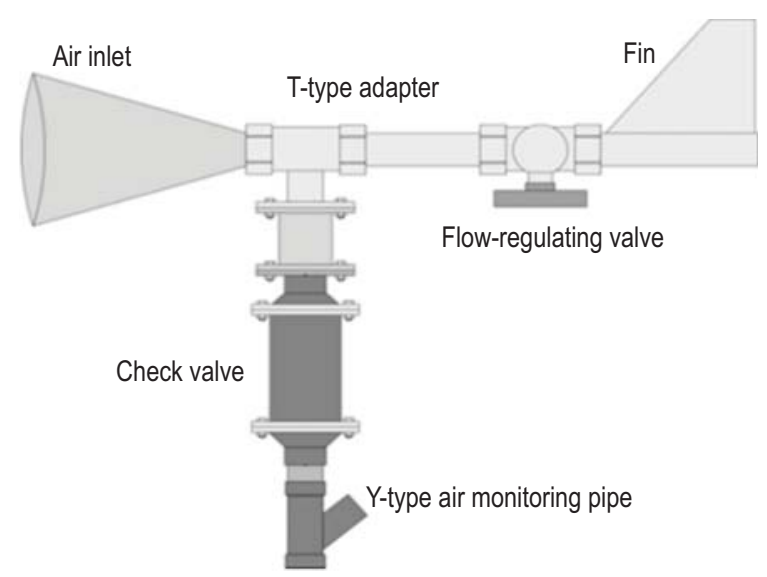

Fig. 1 : Sketch diagram of passive bioventing equipment 
$10 \%$ and wind-driven bioventing systems were then established for the experiment. The man-made wind field was created by adjustable fans and the amount of air introduced into vadose zone was adjusted according to the requirements of the experimental set up. In order to investigate the effects of microorganism and nutrients, soil in the pilot sets were collected weekly to monitor microbial activities, and to analyze the diesel concentration.

Batch respiration experiment of bioslurry method : Bioslurry method increases the chances of interactions between microorganisms and diesel in the soil. According to the results of microbial respiration activity monitored by bioslurry method, the respiration rate was higher by the bioslurry method within four weeks, and the variability was the lowest with a soil:water ratio of 1:3 (Aspray, 2007). Hence, the same ratio was followed in this research. In order to stimulate a diesel-degradation, a bacterium strain was isolated from a diesel-polluted site, and nutrients source and operation conditions were optimized (Dahalan et al., 2014). Based on the results of element analyses, $200 \mathrm{mM}$ urea $\left(\mathrm{NH}_{2} \mathrm{CONH}_{2}\right)$ was added as nitrogen supplement, and $8.06 \mathrm{mM}$ Centrum junior with extra calcium (from Pfizer) was added as phosphor and microelement supplement into bioslurry to conform to the C:N:P ratio of $100: 10: 1$, as suggested in a earlier report
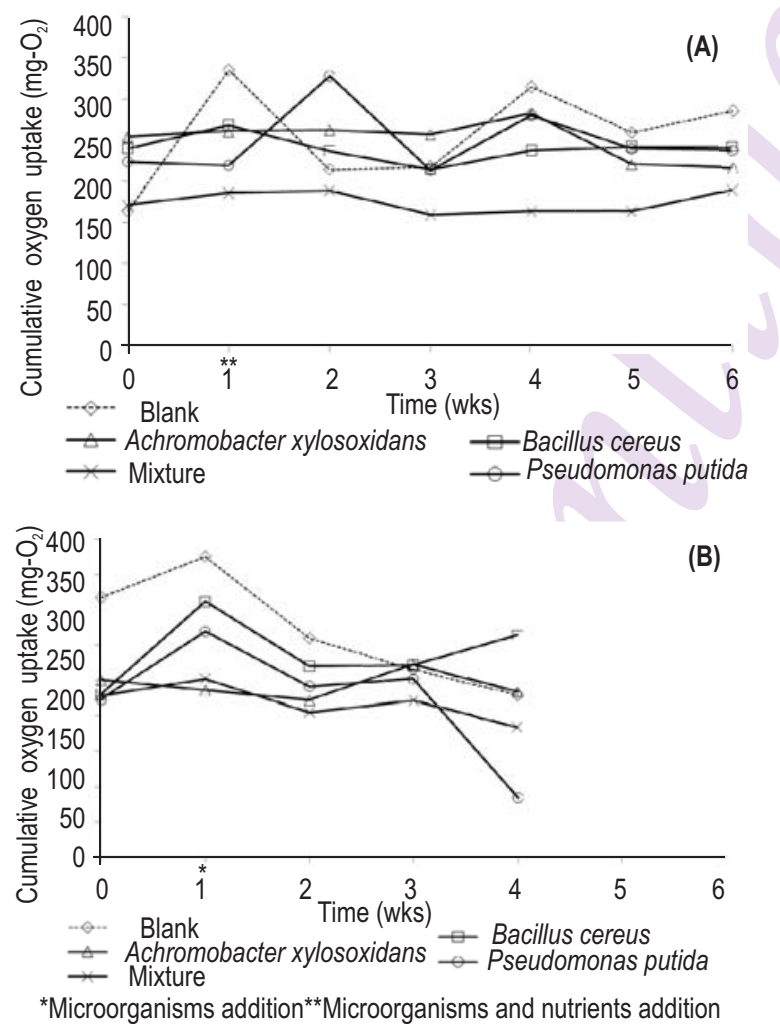

Fig. 2 : The cumulative oxygen uptake of bioventing pilot sets with and without the addition of nutrients. (A) With the addition of microorganisms only; (B) With the addition of microorganisms and nutrients
(Cookson, 1995). In addition, a test tube with $6 \mathrm{~N} \mathrm{KOH}$ solution for absorbing carbon dioxide generated from the experiment was installed. After assembly, the bottle lid with a washer was placed and the bottle was fixed in a thermostat water bath set at $32^{\circ} \mathrm{C}$. The needle was stabbed into the bottle lid in a tilted manner. The pressure of oxygen cylinder was set at 2.2 to $2.5 \mathrm{psi}$, and the stirrer was set at a proper speed. The monitoring software of the bubble respirometer was then launched to record the oxygen uptake of microorganisms in soil. Recording for each batch was conducted for five days. In order to exclude the non-biological oxygen uptake, the background oxygen uptake was measured by a reaction bottle filled with deionization water only. These background values were deducted from each batch measuring data.

Microorganisms capable of degrading diesel : One pilot set was used as a blank without air supplement, and the others were ventilated with enough oxygen into soil zone by an artificial field of wind speed $0.6 \mathrm{~m} / \mathrm{s}$ in passive bioventing equipments. Local bacterial, strains Bacillus subtilis, Achromobacter xylosoxidans and Pseudomonas putida, capable of degrading diesel, were domesticated into experimental pilot sets. To promote adaption to highly diesel contaminated soil, microorganisms were incubated
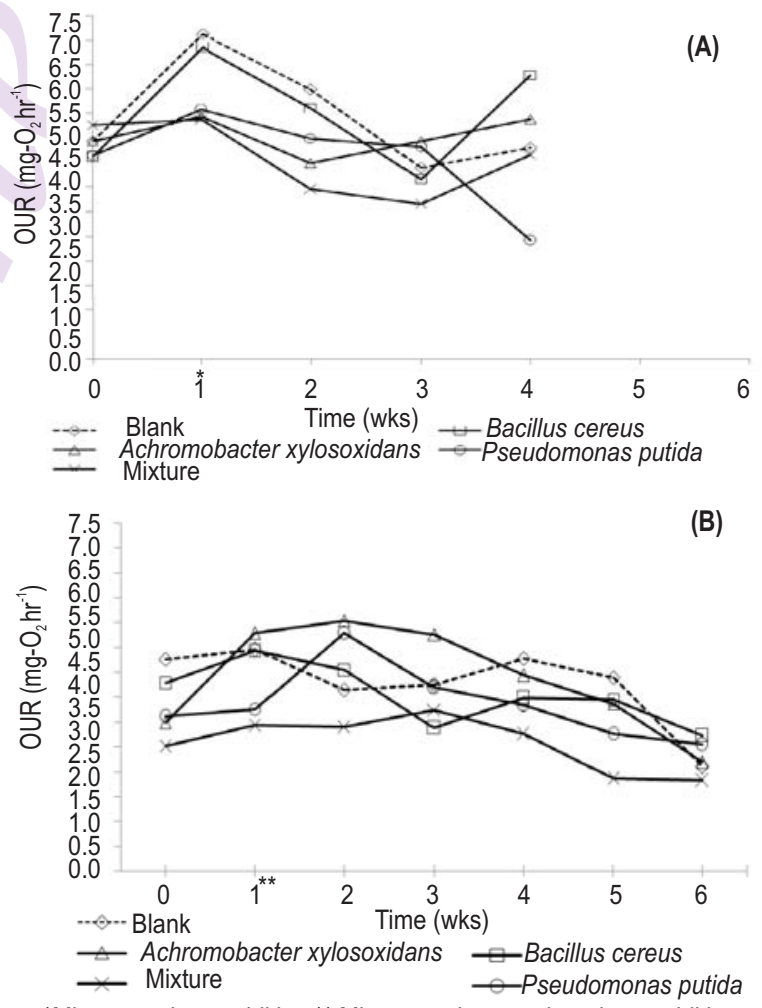

*Microorganisms addition ** Microorganisms and nutrients addition

Fig. 3: The 24-hr average oxygen uptake of bioventing pilot sets with and without the addition of nutrients. (A) With the addition of microorganisms only; (B) With the addition of microorganisms and nutrients 
in liquid Lysogeny broth culture medium and then domesticated into pilot sets. In the following experiments, sufficient nutrients were also provided into pilot sets to create an environment suitable for microbial degradation. Data from experimental pilot sets were compared with the data from blank to evaluate the variability in microbial activity.

\section{Results and Discussion}

Except for the blank pilot, the other four pilot sets with various microorganisms were ventilated for four weeks by passive bioventing equipments to supply enough oxygen during the first phase. In the second phase, the pilot sets were added with various microorganisms and nutrients and were ventilated for six weeks. The nutrients added were formulated by mixing urea $\left(\mathrm{NH}_{2} \mathrm{CONH}_{2}\right)$ solution and commercial phosphorus fertilizer to conform to the C:N:P ratio of $100: 10: 1$. The results and correlations of cumulative oxygen uptake, oxygen uptake rate and diesel degradation trend are discussed as follows.

Without adding nutrients into the bioventing pilot sets, soil samples were taken at week 0 (the start of the pilot experiment) for 5-day batch biological respiration experiment by bubble
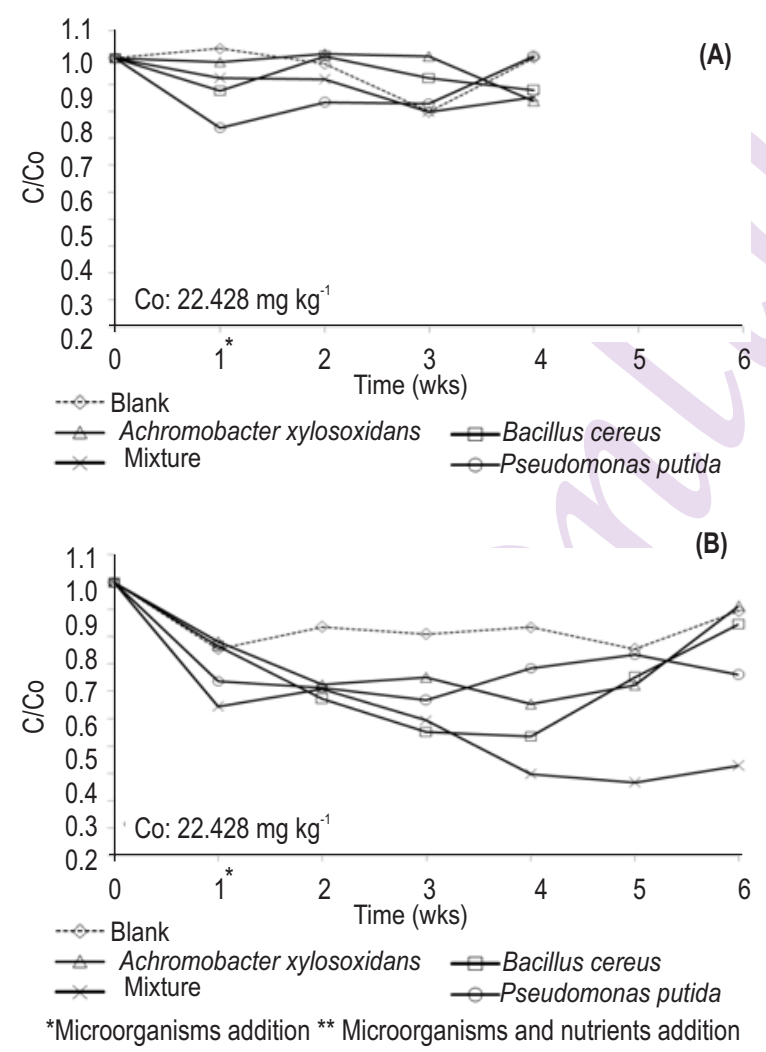

Fig. 4: The relative diesel concentration of bioventing pilot sets without and with the addition of nutrients. (A) With the addition of microorganisms only; (B) With the addition of microorganisms and nutrients respirometer as background data of pilot sets without adding microorganisms. At week 1, the microorganisms capable of degrading diesel, were added. Pilot sets were named by the microorganisms added, such as Bacillus subtilis set, Achromobacter xylosoxidans set, Pseudomonas putida set, and pilot with mixture of three microorganisms was named as mixture set. The cumulative oxygen uptake of these four sets at week 0 were approximately between $200 \mathrm{mg}-\mathrm{O}_{2}$ and $250 \mathrm{mg}-\mathrm{O}_{2}$ in 5-day batch experiment, while the cumulative oxygen uptake of blank was higher, $368 \mathrm{mg}-\mathrm{O}_{2}$. After one week of the addition of microorganisms, the cumulative oxygen uptakes of Bacillus subtilis set and Pseudomonas putida set were substantially elevated, $362 \mathrm{mg}-\mathrm{O}_{2}$ and $319 \mathrm{mg}-\mathrm{O}_{2}$, respectively, suggesting that liquid Lysogeny broth medium could substantially increase the microbial activity. At week 2, the microbial cumulative oxygen uptakes were found decreasing, probably because of the exhaustion of Lysogeny broth medium. At week 3, the cumulative oxygen uptakes of the microorganism sets were kept at the same level or slightly elevated. At week 4, the cumulative oxygen uptake of Bacillus subtilis set increased to $314 \mathrm{mg}-\mathrm{O}_{2}$, while in other sets it decreased. The above findings suggest that Bacillus subtilis set was well-adapted to higher diesel contaminated environment without addition of nutrients (Fig. 2A).

In bioventing pilot sets with addition of microorganisms and nutrients during second phase, the cumulative oxygen uptake in the Bacillus subtilis set was found to be elevated from $239 \mathrm{mg}-\mathrm{O}_{2}$ to $268 \mathrm{mg}-\mathrm{O}_{2}$ at week 1 , and then maintained its level of $237 \mathrm{mg}-\mathrm{O}_{2}$ until week 4 . The cumulative oxygen uptake in the Achromobacter xylosoxidans set was consistent from week 1 to week 4 at $282 \mathrm{mg}-\mathrm{O}_{2}$ and thereafter it decreased. The cumulative oxygen uptake in Pseudomonas putida set elevated from $219 \mathrm{mg}$ $\mathrm{O}_{2}$ to $328 \mathrm{mg}-\mathrm{O}_{2}$ at week 2 and thereafter gradually decreased. The cumulative oxygen uptake in the mixture set was found between $160 \mathrm{mg}-\mathrm{O}_{2}$ and $190 \mathrm{mg}-\mathrm{O}_{2}$ in six weeks (Fig. 2B). The above findings suggest that the microbial activity in the Pseudomonas putida set in a highly diesel contaminated environment was elevated due to addition of nutrients. Nevertheless, the results of cumulative oxygen uptake indicated insignificant difference in soil microbial activity between biostimulation and bioaugmentation, the finding results are in conformity with the findings of Colla et al. (2014) on carbon dioxide evolution demonstrated insignificant difference between biostimulation and bioaugmentation treatments.

Although the cumulative oxygen uptake was optimized in a 5-day respiration experiment, however, a short term indication is needed at remediation site to determine the current microbial activity. Therefore, variability of microbial oxygen uptake rate within 24 hours of each respiration experiment was calculated to find the microbial activity trend, which is quantitatively shown as the arithmetic mean.

After one week, in a experiment of bioventing system without nutrients into the pilot sets, the 24-hr average oxygen 
uptake rate of Bacillus subtilis, Achromobacter xylosoxidans and Pseudomonas putida sets were found to be elevated from $4.1 \mathrm{mg}$ $\mathrm{O}_{2} \mathrm{hr}^{-1}$ to $6.4 \mathrm{mg}-\mathrm{O}_{2} \mathrm{hr}^{-1}$, from $4.4 \mathrm{mg}-\mathrm{O}_{2} \mathrm{hr}^{-1}$ to $4.9 \mathrm{mg}^{-\mathrm{O}_{2}} \mathrm{hr}^{-1}$ and from $4.1 \mathrm{mg}-\mathrm{O}_{2} \mathrm{hr}^{-1}$ to $5.1 \mathrm{mg}-\mathrm{O}_{2} \mathrm{hr}^{-1}$, respectively. These results indicate that microorganisms utilized nutrients from the liquid Lysogeny broth medium. At week 2, due to depletion of the nutrient level, there was decrease in all the oxygen uptake rates. At week 3 , the oxygen uptake rate in the Achromobacter xylosoxidans set increased from $4.0 \mathrm{mg}-\mathrm{O}_{2} \mathrm{hr}^{-1}$ to $4.4 \mathrm{mg}^{-\mathrm{O}_{2}} \mathrm{hr}^{-1}$. While at week 4, in case of Bacillus subtilis set, it increased from $3.6 \mathrm{mg}-\mathrm{O}_{2} \mathrm{hr}^{-1}$ to $5.8 \mathrm{mg}^{-\mathrm{O}_{2}} \mathrm{hr}^{-1}$, while in the mixture set, it increased from $3.1 \mathrm{mg}^{-\mathrm{O}_{2}} \mathrm{hr}^{-1}$ to $4.2 \mathrm{mg}^{-\mathrm{O}_{2}} \mathrm{hr}^{-1}$, respectively. These findings suggest that it took three weeks for microorganisms to gradually increase the activity in the highly diesel contaminated environment without nutrients. The 24-hr average oxygen uptake rate in the Bacillus subtilis set was the higher compared to other sets (Fig. 3A).

In case of bioventing pilot sets with nutrients, a 24-hr average oxygen uptake rate of Bacillus subtilis set was measured as $4.4 \mathrm{mg}_{-} \mathrm{O}_{2} \mathrm{hr}^{-1}$ at week 1 , thereafter, it gradually decreased at a rate $2.9 \mathrm{mg}-\mathrm{O}_{2} \mathrm{hr}^{-1}$ to $3.5 \mathrm{mg}-\mathrm{O}_{2} \mathrm{hr}^{-1}$ until week 4 . The oxygen uptake rate in the Achromobacter xylosoxidans set was steady during first three weeks between $4.8 \mathrm{mg}-\mathrm{O}_{2} \mathrm{hr}^{-1}$ and $5.0 \mathrm{mg}^{-} \mathrm{O}_{2} \mathrm{hr}^{-1}$ and then it gradually decreased. The oxygen uptake rate in the Pseudomonas putida set increased to $4.8 \mathrm{mg}^{-} \mathrm{O}_{2} \mathrm{hr}^{-1}$ in the first two weeks, and then gradually decreased. The oxygen uptake rate of mixture set was in the range of $2.8 \mathrm{mg}-\mathrm{O}_{2} \mathrm{hr}^{-1}$ and $3.2 \mathrm{mg}-\mathrm{O}_{2}$ $\mathrm{hr}^{-1}$ in four weeks. From these results, it can be inferred that the microbial activity in the Achromobacter xylosoxidans set in the highly diesel contaminated environment was the highest on the addition of nutrients (Fig. 3B). In the bioventing pilot sets without nutrients, the relative diesel concentration $\left(C / C_{0}\right)$ was low at week 1 , similar to the microbial activity trend. These results suggest that nutrients in the liquid Lysogeny broth medium might have facilitated the microbial degradation of diesel contamination. However, after depletion of nutrients, degradation stopped, since there was insufficient nutrient in the soil to facilitate microbial degradation. The relative diesel concentration at week 3 and 4 was still up to 0.8 (Fig. 4A).

When the nutrients were added into the bioventing system, the diesel degradation trend in Bacillus subtilis set continued for three weeks, and the relative diesel concentration was 0.45 . Whereas in the case of Achromobacter xylosoxidans set, diesel degradation continued for two weeks and the relative diesel concentration was 0.62. In Pseudomonas putida set, diesel degradation trend remained for only one week, while relative diesel concentration was 0.63 . In the case of mixture set, diesel degradation trend continued for four weeks and the relative diesel concentration reached 0.30 (Fig. 4B). These results are consistent with the conclusion of Kim et al. (2009). According to relative diesel concentration trend of bioventing pilot sets without and with the addition of nutrients in Fig. 4, adding nutrients were necessary to enhance biodegradation of oil pollutant.

The results of the present study concluded that the microbial activity in three sets containing microorganisms increased while relative diesel concentration decreased within four weeks of experimental set up. The finding results are in conformity with the findings of Balba et al. (1998) on the degradation rates for hydrocarbons. In addition, the oxygen uptake rate was higher while high diesel concentration existed in soil, which is consistent with the result of Nwankwo et al. (2014). Based on the results of the respiration experiment, it can be inferred that the 24-hr average oxygen uptake rate was more appropriate measure of biological activity trend as compared to cumulative oxygen uptake, and 24-hr average oxygen uptake rate could serve as an efficient and effective indicator to monitor microbial activity at the diesel contaminated sites.

\section{Acknowledgments}

This study was funded by the research project supported by the Taiwan EPA. The views or opinions expressed in this article are those of the writers and should not be construed as opinions of the Taiwan EPA. Mention of trade names vendor names or commercial products does not constitute endorsement or recommendation by Taiwan EPA.

\section{References}

Adebusoye, S.A., M.O. Ilori, O.O. Amund, O.D. Teniola and S.O. Olatope: Microbial degradation of petroleum hydrocarbons in a polluted tropical stream. World J. Microbiol. Biotechnol., 23, 1149-1159 (2007).

Aspray, T.J., D.J.C. Carvalho and J.C. Philp: Application of soil slurry respirometry to optimize and subsequently monitor ex situ bioremediation of hydrocarbon-contaminated soils. Int. Biodeterior. Biodegrad., 60, 279-284 (2007).

Balba, M.T., N. Al-Awadhi and R. Al-Daher: Bioremediation of oilcontaminated soil: Microbiological methods for feasibility assessment and field evaluation. J. Microbiol. Meth., 32, 155-164 (1998).

Boopathy, R.: Factors limiting bioremediation technologies. Bioresour. Technol., 74, 63-67 (2000).

Brown, R.A., R.E. Hinchee, R.D. Norris and J.T. Wilson: Bioremediation of petroleum hydrocarbons: A flexible, variable speed technology. Remediation, 6, 95-109 (1996).

Chaillan, F., C.H. Chaîneau, V. Point, A. Saliot and J. Oudot: Factors inhibiting bioremediation of soil contaminated with weathered oils and drill cuttings. Environ. Pollut., 144, 255-265 (2006).

Chaîneau, C.H., G. Rougeux, C. Yêprêmian and J. Oudot: Effects of nutrient concentration on the biodegradation of crude oil and associated microbial populations in the soil. Soil Biol. Biochem., 37, 1490-1497 (2005)

Chang, H.Y., J.M. Hung, Y.S. Wu, Y.R. Lin, H.Y. Lai and C.J. Lu: Effect of applying biosolids on the biodegradation of toluene and naphthalene contaminated soils. J. Environ. Biol., 30, 971-975 (2009).

Colla, T.S., R. Andreazza, F. Bücker, M.M. de Souza, L. Tramontini, G.R. Prado, A.P.G. Frazzon, F.A. de Oliveira Camargo and F.M. Bento: 
Bioremediation assessment of diesel biodiesel contaminated soil using an alternative bioaugmentation strategy. Environ. Sci. Pollut. R., 21, 2592-2602 (2014).

Cookson, J.R. Jr.: Bioremediation Engineering: Design and Applications, McGraw-Hill, New York (1995).

Dahalan, F.A., I. Yunus, W.L.W. Johari, M.Y. Shukor, M.I.E. Halmi, N.A. Shamaan and M.A. Syed: Growth kinetics of a diesel-degrading bacterial strain from petroleum-contaminated soil. J. Environ. Biol., 35, 399-406 (2014).

Kim, S.J., D.H. Choi, D.S. Sim and Y.S. Oh: Evaluation of bioremediation effectiveness on crude oil-contaminated sand. Chemosphere, $\mathbf{5 9}$, 845-852 (2005).

Leeson, A. and R.E. Hinchee: Soil Bioventing, Principles and Practices. Lewis Publisher, Florida (1997).

Masy T., S. Demanèche, O. Tromme, P. Thonart, P. Jacques, S. Hiligsmann and T.M. Vogel: Hydrocarbon biostimulation and bioaugmentation in organic carbon and clay-rich soils. Soil Biol. Biochem., 99, 66-74 (2014).
Nwankwo C., R.E. Ikyereve, A. Mohammed, O.S. Falade and K. Salisu: Biodegradability of diesel using specific oxygen uptake rate. Int. J. Eng. Sci. 3, 28-32 (2014).

Plaza, G., K. Ulfig, A. Worsztynowicz, G. Malina, B. Krzeminska and R.L. Brigmon: Respirometry for assessing the biodegradation of petroleum hydrocarbons. Environ. Technol., 26, 161-170 (2005).

Shim, H., B. Hwang, S.S. Lee and S.H. Kong: Kinetics of BTEX biodegradation by a coculture of Pseudomonas putida and Pseudomonas fluorescens under hypoxic conditions. Biodegradation, 16, 319-327 (2005).

Szulc, A., D. Ambrożewicz, M. Sydow, L. Lawniczak, A. PiotrowskaCyplik, R. Marecik and L. Chrzanowski: The influence of bioaugmentation and biosurfactant addition on bioremediation efficiency of diesel-oil contaminated soil Feasibility during field studies. J. Environ. Manage.,132, 121-128 (2014).

Texas Research Institute: Laboratory scale gasoline spill and venting experiment. American Petroleum Institute, Interim Report No. 7743-5: JST (1980). 